\title{
MORFOANATOMIA FOLIAR EM MUDAS DE Schinus terebinthifolius SOB DIFERENTES NÍVEIS DE SATURAÇÃO HÍDRICA
}

\author{
Fernanda Almeida Grisi ${ }^{1}$, Alessandro Camargo Angelo ${ }^{2}$, Maria Regina Torres Boeger ${ }^{3}$, \\ Carlos André Espolador Leitão ${ }^{4}$, Sara Fernandes Galvão ${ }^{5}$, Ivar Wendling ${ }^{6}$ \\ ${ }^{1}$ Enga ${ }^{a}$ Agrônoma, Dr., Vitória da Conquista, BA, Brasil - fergrisi@ yahoo.com.br \\ ${ }^{2}$ Eng. Florestal, Dr., Depto. de Ciências Florestais, UFPR, Curitiba, PR, Brasil - alessandro.angelo@ufpr.br \\ ${ }^{3}$ Bióloga, Dra ${ }^{\mathrm{a}}$, Depto. de Botânica, UFPR, Curitiba, PR, Brasil - rboeger@ufpr.br \\ ${ }^{4}$ Biólogo, Dr., Depto. de Ciências Naturais, UESB, Vitória da Conquista, BA, Brasil - candreel@ yahoo.com.br \\ ${ }^{5}$ Bióloga, Mestranda em Botânica, UFV, Viçosa, MG, Brasil - sarafergal@ gmail.com \\ ${ }^{6}$ Eng. Florestal, Dr., EMBRAPA Florestas, Colombo, PR, Brasil - ivar@ cnpf.embrapa.br
}

Recebido para publicação: 03/03/2010 - Aceito para publicação: 07/06/2011

\begin{abstract}
Resumo
As características morfológicas e anatômicas foliares de espécies vegetais são importantes indicadores de sua ecologia e de seus hábitats. Objetivou-se caracterizar a plasticidade fenotípica de Schinus terebinthifolius Raddi em diferentes condições de saturação hídrica. As mudas foram produzidas em tubetes plásticos, permanecendo em estufa por quatro meses, sendo irrigadas normalmente. Em seguida foram submetidas aos tratamentos: T1- testemunha, T2- alagamento parcial e T3- alagamento total. Após três semanas sob alagamento, foram realizadas descrições anatômicas foliares comparativas e avaliadas as características morfológicas área foliar, área específica foliar, espessura foliar, teor de água e densidade estomática. Durante 10 semanas foram observadas as modificações fenotípicas adaptativas. Foi observado aumento da espessura da base do caule, clorose e abscisão foliar, surgimento de lenticelas e raízes adventícias. Após três semanas de alagamento, não foram verificadas grandes modificações na morfologia das folhas, principalmente para a AF e AEF. Em T3, o teor de água foi maior e a espessura foliar menor. Não houve diferença entre os tratamentos para DE. Quanto aos aspectos anatômicos, observou-se uma redução na espessura do mesofilo e das nervuras, assim como a produção de compostos fenólicos por alguns tipos celulares. Os espaços intercelulares são progressivamente mais amplos nas plantas submetidas ao alagamento.

Palavras-chave: Morfometria; alagamento; plasticidade fenotípica; descrição anatômica.
\end{abstract}

\begin{abstract}
Leaf morphoanatomy in seedlings of Schinus terebinthifolius, under different levels of water saturation. The morphological and anatomical leaf characteristics plant species are important indicators of their ecology and habitat The purpose of this work was to characterize the phenotypic plasticity of Schinus terebinthifolius Raddi in different conditions of water saturation. The seedlings were grown in plastic tubets, kept in a greenhouse for four months, and irrigated normally. Then they were treated: T1-control, T2-partial flooding and T3- total flooding. After three weeks under flooding leaf comparative anatomical descriptions were done and the following morphological characteristics were assessed: leaf area, specific leaf area, leaf thickness, water content and stomatal density. Over 10 weeks, were observed the adaptive phenotypic changes. We observed an increase in thickness of the base of the stem, leaf chlorosis and abscission, and the appearance of lenticels and adventitious roots. After three weeks of flooding, there were no major changes in the morphology of the leaves, mainly to $\mathrm{AF}$ and AEF. In T3, the water content was higher and leaf thickness. There was no difference between treatments for DE. Concerning the anatomy, we noticed that there was a reduction in the thickness of the mesophyll and vein as well as the production of phenolic compounds by some cell types. The intercellular spaces are progressively larger in plants subjected to flooding.
\end{abstract}

Keywords: Morphometry; flooding; phenotypic plasticity; anatomical description.

\section{INTRODUÇÃO}

As matas ciliares são imprescindíveis ao equilíbrio ecológico de uma bacia hidrográfica e, por estarem diretamente associadas aos cursos d'água, sofrem alagamentos periódicos, decorrentes de cheias. 
O alagamento é um forte fator limitante à vida de inúmeras espécies vegetais. Assim, torna-se importante o estudo da tolerância ou resistência de espécies de mata ciliar a alagamentos temporários ou duradouros (CIRILO; MEDRI, 2002). Schinus terebinthifolius Raddi (aroeira-vermelha) é uma árvore com aplicações múltiplas, tais como madeireira, ornamental e fitoquímica, servindo também para arborização e recuperação de áreas degradadas. Ecologicamente é classificada como planta perenifólia, heliófita e pioneira, comum em beira de rios, córregos e em várzeas úmidas de formações secundárias, contudo cresce também em terrenos secos e pobres (LORENZI, 2001).

As plantas sensíveis à inundação são danificadas severamente em poucas horas sob anoxia, enquanto as plantas tolerantes podem suportar temporariamente essa condição. Já as plantas bem adaptadas, que habitam terras úmidas, crescem e sobrevivem durante períodos superiores a meses com seus sistemas de raízes em condições de alagamento (TAIZ; ZEIGER, 2004). A saturação hídrica do solo pode afetar o crescimento de raízes e também da parte aérea das plantas, tanto pela inibição do alongamento dos entrenós quanto pela iniciação e expansão das folhas, podendo também acelerar a senescência e abscisão destas (KOZLOWSKI, 1984). O alagamento do solo reduz a disponibilidade de oxigênio para a planta. No entanto, determinadas espécies, quando submetidas ao alagamento, podem produzir modificações morfoanatômicas, as quais permitem a difusão de oxigênio da parte aérea para as raízes, mantendo a respiração aeróbica. Essas modificações incluem lenticelas hipertróficas e formação de aerênquima e de raízes adventícias (MEDRI et al., 1998).

As lenticelas são aberturas comuns na periderme de caules e raízes, com função de trocas gasosas, podendo ou não estar associadas com locais de existência de estômatos. Na região das lenticelas, o felogênio é mais ativo e produz um tecido que, em contraste com o súber, apresenta inúmeros espaços intercelulares (GAVILANES; CASTRO, 1998). Em caules submersos, as lenticelas sofrem hipertrofia na região submersa e acima dela, com aumento do tecido de preenchimento e dos espaços intercelulares e, consequentemente, da aeração (APPEZZATO-DA-GLÓRIA; CARMELO-GUERREIRO, 2003). Plantas que crescem em ambientes que promovam hipoxia podem desenvolver aerênquimas, cujos espaços intercelulares amplos envolvem destruição de células durante sua formação. Tal tecido é uma adaptação à condição de alagamento (ESAU, 1976). Em solos pouco arejados, as plantas que ali crescem desenvolvem sistema de raízes laterais, posicionando-as próximas à superfície do substrato (LARCHER, 2000).

Segundo Lobo e Joly (2001), ao contrário do que sugerem alguns autores, o estudo isolado das respostas do metabolismo respiratório do sistema radicial ou de rizomas submetidos a saturação hídrica do solo não permite a classificação das espécies em tolerantes ou não tolerantes ao estresse. Variações na estrutura das folhas de angiospermas são, em grande parte, relacionadas com o hábitat, e a disponibilidade de água é um fator especialmente importante que afeta sua forma e estrutura (RAVEN et al., 2001). Estudos anatômicos são altamente significativos, especialmente quando associados aos aspectos ecológicos, fisiológicos e comparativos (METCALFE; CHALK, 1950). A anatomia foliar é um fator de bastante importância, pois dela depende, em grande parte, a adaptação das plantas ao seu ambiente. São as características químicas e/ou morfológicas da superfície foliar que condicionam, por exemplo, a quantidade de luz absorvida ou refletida, o grau de hidrofobia do órgão, a pressão de vapor do ar em contato com as folhas, a eficiência do órgão em defender-se de parasitas e patógenos, a quantidade de poluentes ou defensivos absorvida e, evidentemente, a magnitude da transpiração (SANTIAGO et al., 2001). De acordo com os estudos de Dias et al. (2003), ficou demonstrado que as estruturas histológicas de folhas de $S$. terebinthifolius expressam características fenotípicas distintas em função das condições ambientais.

A área foliar, a área específica foliar, a espessura total da lâmina foliar, o conteúdo de água e a densidade estomática são alguns parâmetros utilizados para avaliar o grau de adaptação da planta a determinados ambientes. A escassez de informações anatômicas foliares sobre aroeira-vermelha requer estudos sobre uma possível plasticidade anatômica através da análise de influências ambientais. Investigar a associação da variação das características morfoanatômicas das folhas com variáveis ambientais, como a saturação hídrica, fornece informações sobre as respostas da planta às condições ecológicas. É esperado que as mudas de aroeira-vermelha demonstrem seu potencial de utilização em recuperação de áreas ripárias, por apresentarem modificações morfoanatômicas oriundas de condições de alagamento.

Apesar da grande importância econômica e ecológica da aroeira-vermelha e de seu potencial na recuperação de áreas degradadas, as informações sobre as respostas morfoanatômicas sob condições de alagamento ainda carecem de complementações. No intuito de contribuir com o conhecimento sobre a utilização da aroeira-vermelha em programas de recuperação de áreas ripárias, o presente trabalho teve como objetivo caracterizar a plasticidade fenotípica da aroeira-vermelha em diferentes condições de saturação hídrica, mediante análise de aspectos morfoanatômicos. 


\section{MATERIAL E MÉTODOS}

\section{Cultivo e obtenção das amostras}

$\mathrm{O}$ experimento foi conduzido no viveiro da Embrapa Florestas em Colombo (PR), localizado a $22^{\circ} 42^{\prime} 30^{\prime}$ ' S e $47^{\circ} 38^{\prime} 00^{\prime}$ W, com altitude média de $950 \mathrm{~m}$. O clima é Cfb, segundo a classificação de Köppen, com precipitação média anual de $1.600 \mathrm{~mm}$. A temperatura média anual é de $16,5^{\circ} \mathrm{C}$, a temperatura média do mês mais frio é de $12,6^{\circ} \mathrm{C}$ e a do mês mais quente é de $20,1^{\circ} \mathrm{C}$.

As mudas de aroeira foram produzidas em tubetes plásticos com volume de $188 \mathrm{~cm}^{3}$, contendo substrato comercial Plantmax ${ }^{\circledR}(90 \%)$, terra de subsolo (10\%) e adubação de base para espécies florestais nativas (superfosfato simples, sulfato de amônio, cloreto de potássio e FTE BR9), dispostos em três bandejas metálicas com capacidade para 536 mudas, preenchidas até um terço de sua capacidade, permanecendo em estufa por quatro meses, onde as mudas foram adubadas por três vezes. Em seguida, as mudas foram transferidas para bandejas plásticas com capacidade para 96 tubetes, sendo preenchidas até a metade de sua capacidade, de forma espaçada, e submetidas a um período de pleno sol.

Caixas de madeira medindo $3,0 \mathrm{~m}$ (comprimento) x $0,8 \mathrm{~m}$ (largura) e $0,6 \mathrm{~m}$ (altura) foram fabricadas para acondicionar as bandejas com os tubetes. Primeiro, as caixas que receberiam o tratamento de inundação foram recobertas por dentro com plástico. Após as bandejas serem dispostas dentro das caixas, uma delas foi preenchida com água até a altura do coleto das mudas e a outra cheia até a submersão das mudas com uma coluna de água de aproximadamente $15 \mathrm{~cm}$. Nessas caixas, as mudas foram submetidas aos tratamentos $\mathrm{T} 1$ - testemunha (plantas irrigadas diariamente, similar à capacidade de campo), T2- alagamento parcial (plantas alagadas até o coleto) e T3- alagamento total (plantas submersas). O delineamento experimental utilizado foi em blocos utilizando pseudorrepetições (HURLBERT, 1984). Na comparação dos três tratamentos, deve-se levar em conta que as caixas diferenciavam-se apenas pelos níveis de alagamento e ausência deste, cada uma formando um único bloco e que, portanto, do ponto de vista estatístico, suas parcelas constituíam-se em pseudorrepetições. Cada tratamento foi composto de cinco parcelas, cada uma com 48 mudas. Durante o período experimental, o ensaio foi conduzido em estufa construída de material vítreo e sem climatização.

As mudas foram avaliadas após três semanas de alagamento. Esse período foi determinado para coleta em função da abscisão foliar das mudas do tratamento totalmente alagado, que se tornava bastante evidenciada. Coletaram-se três folhas localizadas entre o terceiro e o quinto nós no sentido ápice-base de cada indivíduo, respectivamente, folhas 1,2 e 3 . Foram utilizados dez indivíduos por tratamento para as características morfológicas e anatômicas. As demais observações adaptativas foram realizadas semanalmente no período de 70 dias.

\section{Mensurações}

A espessura foliar foi medida com paquímetro digital, com padronização em relação à localização da medida e à ausência de nervuras grossas. Para cálculo da área foliar (folha completa com todos os folíolos), foram utilizadas imagens digitalizadas em escâner de mesa, acoplado ao computador Programa Sigma Scan-Pro versão 5.0 (SPSS Inc., Chicago, IL, USA, 1995). A massa seca das folhas foi obtida mediante secagem a $65{ }^{\circ} \mathrm{C}$, até adquirir peso constante. $\mathrm{O}$ teor de água foi calculado pela representatividade percentual da diferença entre a massa fresca e a massa seca em relação à massa fresca. A área específica foliar (AEF) foi estimada pela relação área foliar/massa seca (WITKOWSKI; LAMONT, 1991). Nas folhas secas, foi estimada a densidade estomática a partir da confecção de moldes da face abaxial da epiderme com esmalte de unha incolor, pela contagem dos estômatos situados numa área previamente conhecida, em microscópio com câmara clara (BOEGER et al., 2006).

As análises estatísticas foram realizadas pelo Programa SAEG versão 8.0, e as comparações de médias pelo teste $\mathrm{T}$ a $5 \%$ de probabilidade.

\section{Caracterização anatômica}

Foram obtidas amostras da região mediana da lâmina foliar e fixadas em FAA (formaldeído, ácido acético, etanol a 50\%, 1:1:18 v/v/v) (JOHANSEN, 1940). Elas foram preservadas temporariamente em etanol a 50\%. As amostras, posteriormente, foram desidratadas em série etílica/butílica terciária, para inclusão em parafina sob vácuo (LEITÃO; CORTELAZZO, 2008), sendo obtidos cortes seriados longitudinais e transversais mediante emprego de um micrótomo rotativo regulado para $8 \mu \mathrm{m}$. Os cortes 
foram afixados em lâminas previamente tratadas com adesivo de Haupt, depois foram desparafinizados, hidratados e corados com azul de toluidina (Colour Index - C.I. 52040) a 0,025\% em tampão Mcllvaine pH 4,0 (VIDAL), para caracterização estrutural e obtenção de metacromasia. Para montagem das lâminas, utilizou-se bálsamo-do-canadá (BERLYN; MIKSCHE, 1976) ou água (JOHANSEN, 1940). Para a documentação fotográfica, utilizou-se um microscópio fotônico, equipado com recurso de captura de imagem digital. Os procedimentos supracitados foram realizados utilizando-se cinco indivíduos em cada tratamento.

\section{RESULTADOS E DISCUSSÃO}

\section{Parâmetros morfológicos (Figura 1)}

De forma geral para os parâmetros morfológicos avaliados após três semanas de alagamento, não foram observadas grandes modificações na morfologia das folhas, mostrando que esses parâmetros são inerentes a esse tipo de condição, ou, por outro lado, indicam um certo grau de tolerância ao alagamento. Outro fator a ser considerado diz respeito à pressão do estresse a que as mudas foram submetidas, o qual pode não ter sido suficientemente forte para modificar a morfologia foliar. Resultados semelhantes foram descritos em carnaúba (Copernicia prunifera (Mill.) H. E. Moore), na qual o alagamento do solo não afetou o crescimento da parte aérea, indicando que essa espécie apresenta alguma tolerância a tal condição (ARRUDA; CALBO, 2004).

Para a área foliar, houve diferença significativa entre os tratamentos apenas para a folha 3 . As folhas pertencentes ao quinto nó do tratamento totalmente alagado apresentaram menor área foliar do que os demais tratamentos. Visando elucidar aspectos da tolerância à hipoxia em plantas de Cecropia pachystachya, Batista et al. (2008) observaram que a taxa de crescimento relativo (TCR) da raiz e do caule foi inferior em plantas alagadas, não havendo diferenças nessa taxa para as folhas e para a planta inteira. A não variação na TCR das folhas pode ter sido em função da maior esclerofilia foliar das plantas alagadas, que apresentaram menor área. Também foram observadas alterações morfoanatômicas em caules e principalmente em raízes de plantas alagadas.

A área específica foliar (AEF) relaciona a superfície da folha com o seu próprio peso, significando a disponibilidade de área por grama de folha. Em S. terebinthifolius, a AEF da folha 3 foi menor para as mudas dos tratamentos T1 e T2, indicando que essas folhas foram as mais espessas, de modo que em T3 as folhas foram menos espessas, pois apresentaram maior AEF. Essa medida é importante para se entenderem as relações hídricas da vegetação e os ciclos de carbono, porque descreve a alocação da biomassa da folha por unidade de área da folha (ARAÚJO; HARIDASAN, 2007).

Quando o alagamento se estende a uma total ou parcial submersão do caule e folhas, as consequências para a vegetação são ainda maiores do que quando o solo é apenas encharcado, pois a submersão restringe a oxigenação e também o suprimento de dióxido de carbono para a fotossíntese. Além disso, com a submersão das folhas, a radiação incidente sobre elas fica reduzida, já que a luz é exponencialmente atenuada com o aumento da profundidade da água (CRAWFORD, 1992; ARMSTRONG et al., 1994).

Verificou-se que a espessura foliar foi menor em T3, concordando com os dados anteriores de AEF. Como esperado, o conteúdo de água foi maior em T3, já que as folhas estavam totalmente submersas. Para o tratamento T2, foi observado o menor teor de água, entretanto as folhas não apresentaram nenhum sintoma de murcha. Sabe-se que a permeabilidade mais baixa das raízes à água frequentemente leva a um decréscimo do potencial hídrico da folha e à murcha, embora esse decréscimo seja temporário se os estômatos se fecharem, evitando mais perda de água por transpiração (TAIZ; ZEIGER, 2004). Portanto, a manutenção da turgidez das folhas em T2 possivelmente se deve a um tipo de resposta foliar para o excesso de água presente nas raízes.

Para a densidade estomática não foi observada diferença significativa entre os tratamentos, não havendo ao menos uma linha de tendência característica. Em geral, o número de estômatos por unidade de área foliar é maior em condições secas do que quando as plantas crescem sob condições úmidas. Isso é atribuído principalmente a uma redução na expansão das folhas de plantas que se encontram sob condições secas (SUTCLIFFE, 1980). Para aroeira-vermelha, essa característica pode não estar ligada a um mecanismo de tolerância ao alagamento. Em um estudo com indivíduos de S. terebinthifolius crescendo em área aberta e em capoeira, também não foi verificada diferença estatística para densidade estomática (CHIAMOLERA, 2008). 

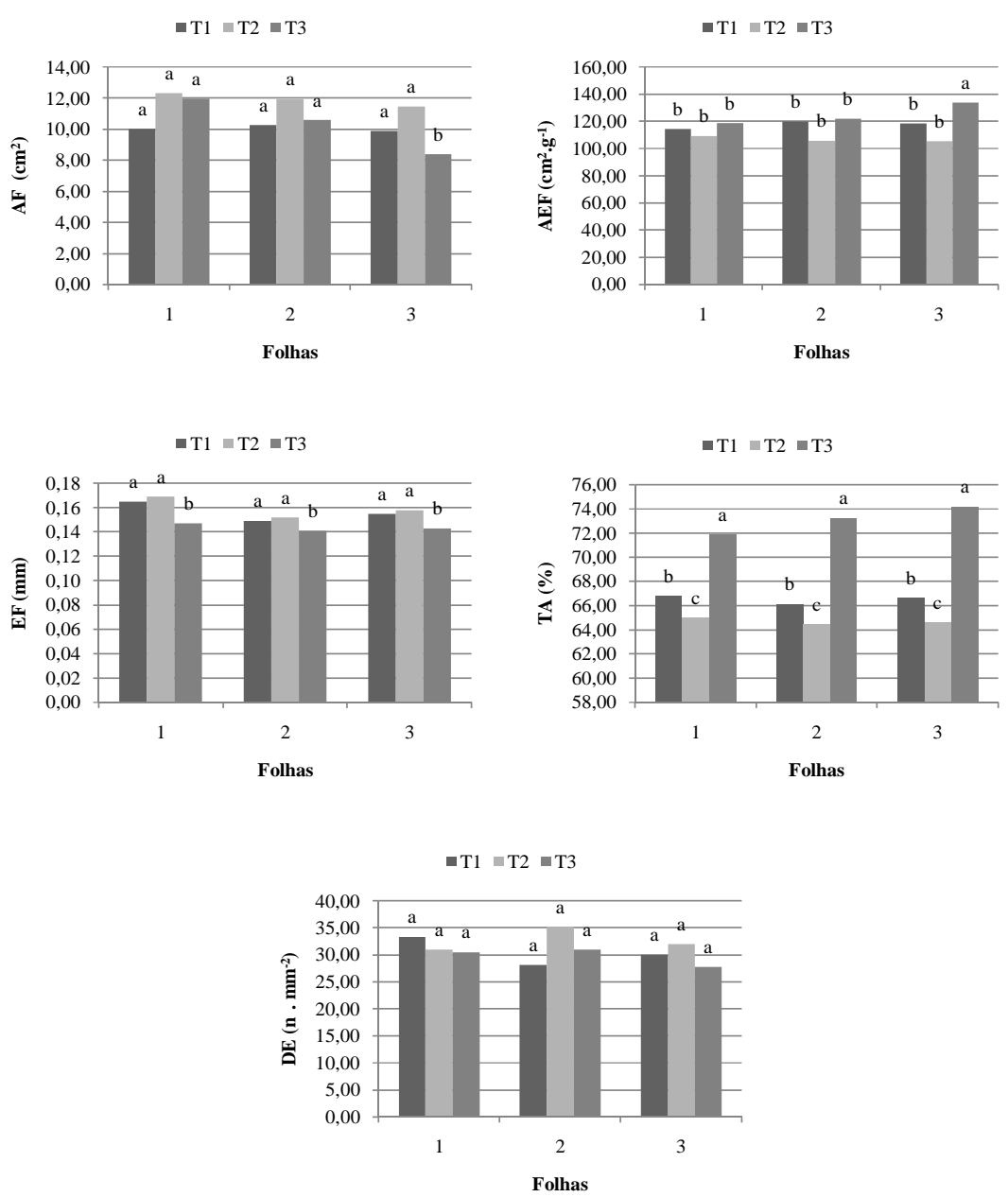

Figura 1. Área foliar (AF), área específica foliar (AEF), espessura foliar (EF), teor de água foliar (TA) e densidade estomática (DE) após três semanas da indução aos tratamentos em mudas de aroeiravermelha. T1: testemunha (plantas irrigadas diariamente), T2: alagamento parcial (plantas alagadas até o coleto) e T3: alagamento total (plantas submersas). Valores médios seguidos de mesma letra para cada folha não diferem significativamente pelo teste $\mathrm{T}$, a $5 \%$ de probabilidade.

Figure 1. Leaf area (LA), specific leaf area (AEF), leaf thickness (EF), leaf water content (TA) and stomatal density (ED) after three weeks of induction treatments on seedlings of Brazilian pepper. T1: control (irrigated plants), T2: partial flooding (flooded plants up to the collar) and total T3: flooding (submerged plants). Mean values followed by same letter for each leaf did not differ significantly by $\mathrm{T}$ test at $5 \%$ probability.

\section{Modificações fenotípicas adaptativas (Figura 2)}

Com o alagamento parcial (T2) das mudas, foi observado, a partir da segunda semana, o aumento visual da espessura da base do caule, com o surgimento de lenticelas que posteriormente tornaram-se hipertrofiadas. $\mathrm{O}$ aparecimento de raízes adventícias só aconteceu a partir da quarta semana sob alagamento parcial. Resultados semelhantes foram obtidos por Pimenta et al. (1996) estudando Jacaranda puberula Cham. (Bignoniaceae) em condições de hipoxia por alagamento, em que observaram um significativo aumento da espessura da base do caule, com hipertrofia das células do tecido cortical, provocando inclusive rachaduras verticais pronunciadas. $\mathrm{O}$ desenvolvimento das plantas foi bastante afetado pelo alagamento, com abscisão de um grande número de folhas. 

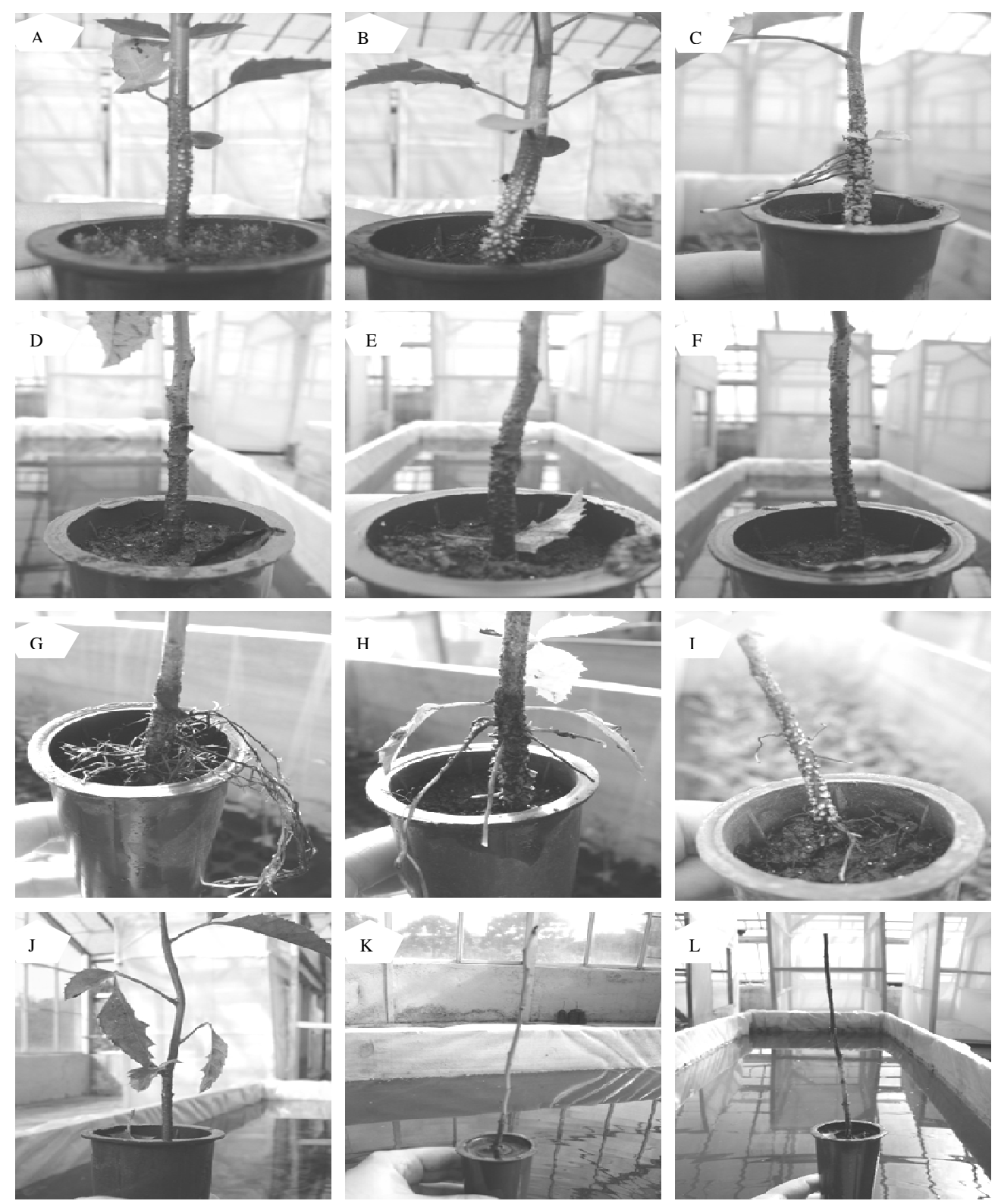

Figura 2. Adaptações fenotípicas apresentadas por mudas de aroeira-vermelha ao longo das semanas sob diferentes condições de alagamento. Formação das lenticelas (A), engrossamento da base do caule (B), lenticelas hipertrofiadas e raízes adventícias (C), em mudas parcialmente alagadas (T2). Formação de lenticelas (D, E, F) em mudas totalmente alagadas (T3). Morte de raízes (G), deterioração das lenticelas hipertrofiadas $(\mathrm{H})$, tendência ao tombamento (I) em mudas T2. Epinastia e abscisão foliar (J), escurecimento do caule (K, L) em mudas de T3. T1: testemunha (plantas irrigadas diariamente), T2: alagamento parcial (plantas alagadas até o coleto) e T3: alagamento total (plantas submersas).

Figure 2. Phenotypic adaptations made by aroeira-vermelha seedlings in the weeks under different conditions of flooding. Formation of lenticels (A), thickening of the stem (B), hypertrophic lenticels and adventitious roots (C) in seedlings partially flooded (T2). Lenticels (D, E, F) completely flooded seedlings (T3). Dead roots $(\mathrm{G})$, deterioration of hypertrophic lenticels $(\mathrm{H})$, tendency to tip over (I) in T2 seedlings. Epinasty and leaf abscission (J), browning of the stem $(\mathrm{K}, \mathrm{L})$ in seedlings of T3. T1: control (irrigated plants), T2: partial flooding (flooded plants up to the collar) and total T3: flooding (submerged plants). 
De acordo com Kolb et al. (1998), nos estudos da anatomia ecológica de Sebastiana commersoniana (Baillon) Smith \& Downs (Euphorbiaceae), plantas alagadas desenvolveram lenticelas hipertróficas caulinares e algumas raízes adventícias. Davanso et al. (2002) observaram as modificações em Tabebuia avellanodae Lor. ex Griseb. (Bignoniaceae), que foi capaz de se adaptar a curtos períodos de alagamento. Isso se deve à capacidade de desenvolver estruturas que amenizam os efeitos do alagamento, promovendo uma difusão interna de oxigênio da parte aérea para as raízes, tais como rachaduras caulinares, raízes superficiais e lenticelas hipertrofiadas nas raízes.

$\mathrm{O}$ alagamento total (T3) das mudas produziu rachaduras caulinares, que surgiram na segunda semana. A partir da terceira semana, as lenticelas começaram a aumentar em tamanho e quantidade, entretanto sem apresentar hipertrofia característica, que consiste em protuberâncias esbranquiçadas. Durante essas semanas, em lugar de raízes adventícias, as mudas do tratamento T3 apresentaram epinastia, ou seja, a curvatura das folhas para baixo, e abscisão foliar. Tais efeitos, dependendo da espécie, podem não ocorrer em plantas submetidas ao alagamento.

Medri et al. (2007), pesquisando Lithraea molleoides (Vell.) (Anacardiaceae), constataram que as plantas alagadas não apresentaram morte de raízes ou abscisão de folhas. $\mathrm{Na}$ base dos caules dessas plantas surgiram lenticelas hipertrofiadas. De acordo com Taiz e Zeiger (2004), condições de estresse aumentam a produção do hormônio etileno, que induz a epinastia. Isso ocorre quando o precursor do etileno é transportado das raízes para a parte aérea. Esses mesmos autores fazem inferências sobre as evidências diretas do envolvimento do etileno na regulação da senescência foliar.

Em T. avellanedae, verificou-se que o alagamento e uma aplicação de "Ethrel" provocaram redução do crescimento e epinastia. Uma aplicação de nitrato de prata amenizou em certos aspectos esses efeitos. Alguns sintomas apresentados durante a inundação e a capacidade de desenvolver estruturas que amenizam os efeitos da hipoxia, como rachaduras corticais e hipertrofia de lenticelas nas raízes, podem estar relacionados a aumentos na concentração de etileno nos tecidos da planta (DAVANSO et al., 2003).

Sob condições de hipoxia, o crescimento da raiz é interrompido, morrem os ápices do sistema radicial, que entram em regiões da rizosfera com baixa concentração de oxigênio, e raízes adventícias se desenvolvem. Sob total ou quase total privação de oxigênio (anoxia), a respiração altera-se para uma desassimilação anaeróbia. Na ausência da oxidação terminal, o acetaldeído e o etanol acumulam-se. O ácido abscísico, o etileno e os precursores do etileno são formados em grandes quantidades, induzindo nas folhas um fechamento parcial dos estômatos, epinastia e frequentemente abscisão (LARCHER, 2000).

As folhas do tratamento T1 apresentaram clorose a partir da sétima semana, uma vez que a última adubação foi realizada três semanas antes do início do experimento. As mudas do tratamento T2 começaram a apresentar clorose na mesma semana do tratamento $\mathrm{T} 1$ e as mudas do tratamento $\mathrm{T} 3$ apresentaram esse sintoma já na segunda semana. A simulação de alagamento ao longo do tempo leva a um esgotamento de nutrientes do solo, o que pode acentuar a clorose (ISHIDA et al., 2002). O alagamento do solo faz decrescer a concentração de nitrogênio e o conteúdo total de nitrogênio nos tecidos das plantas intolerantes ao alagamento (PEZESHKI, 1994; KOZLOWSKI, 2002), o que pode ser atribuído ao declínio na disponibilidade de nitrato no solo, bem como ao declínio na absorção e na assimilação do nitrogênio (PEZESHKI, 1994). Embora sejam características do solo que determinam a intensidade das modificações na solução, a presença de plantas determinará alterações no processo, quer pela absorção de nutrientes, quer por modificações na rizosfera.

A partir da nona semana as mudas do tratamento T2 começaram a apresentar morte de parte das raízes e deterioração das lenticelas hipertrofiadas, além de tendência ao tombamento. Possivelmente tratase de um enfraquecimento decorrente do afrouxamento das células da base do caule, concomitante ao aumento de peso da parte aérea devido ao crescimento. As mudas do tratamento T3, além de apresentarem abscisão foliar bastante significativa, mostravam um escurecimento basípeto do caule, configurando uma necrose generalizada.

Resultados semelhantes foram relatados por Bianchini et al. (2000), estudando as alterações anatômicas em plantas de Chorisia speciosa A. St.-Hil. (Bombacaceae), nas quais o alagamento causou a morte de parte das raízes originais e as raízes restantes apresentaram baixa capacidade de regeneração. As plantas alagadas cresceram menos que o controle e formaram um grande número de lenticelas hipertrofiadas.

\section{Características anatômicas foliares (Figura 3)}

As folhas de S. terebinthifolius normalmente irrigadas (T1) possuem epiderme tabular, cujas células têm paredes periclinais mais espessas que as anticlinais, observando-se campos de pontoação primária nestas últimas. A epiderme apresenta cutícula delgada e com ornamentações com formato de 
estrias paralelas e sinuosas. A folha é hipoestomática (Figura 3E), os estômatos são do tipo anomocítico, corroborando as informações de Metcalfe e Chalk (1950) para a família Anacardiaceae. Os estômatos estão no mesmo nível das células ordinárias ou pouco mais elevados (Figura 3D).

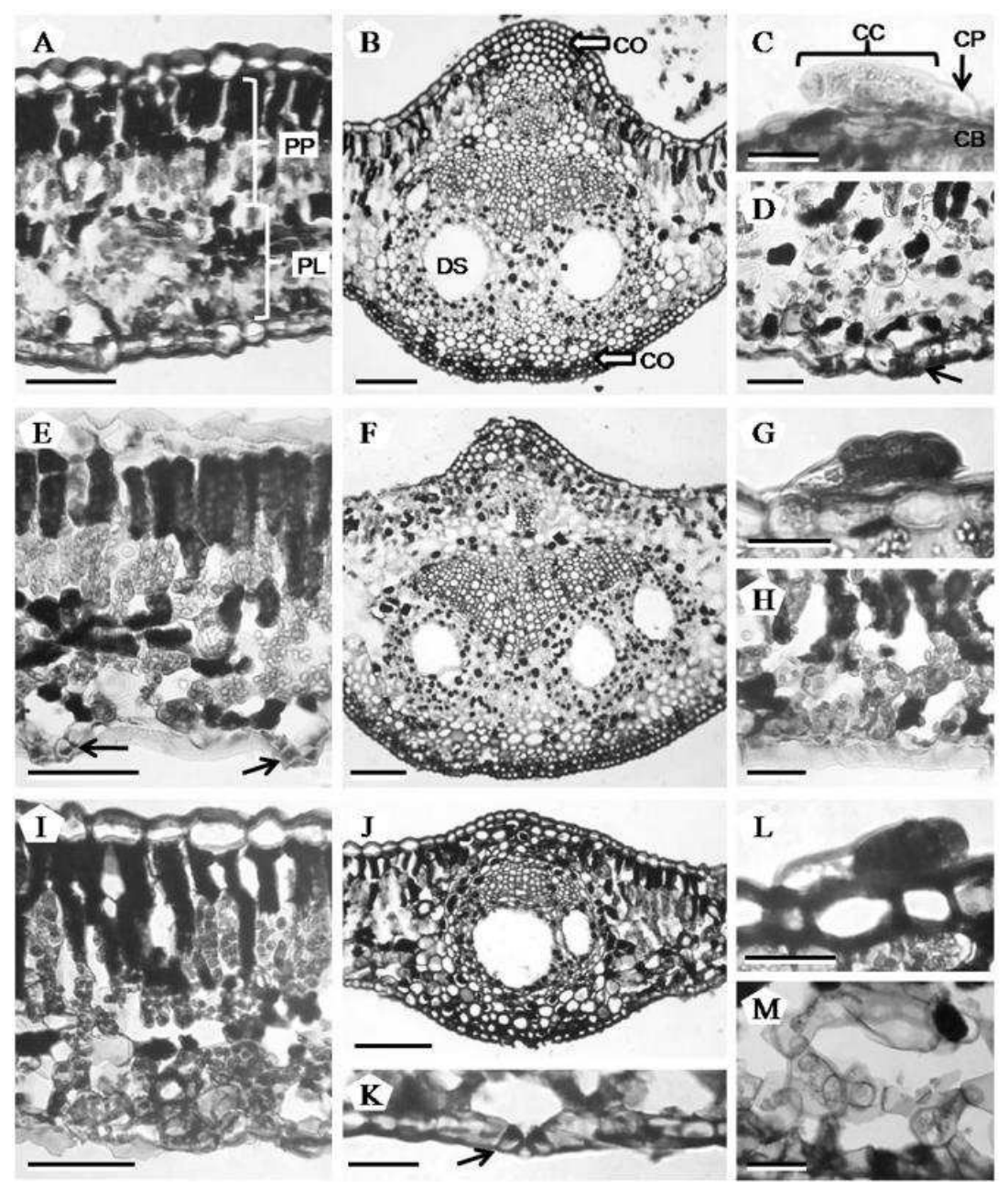

Figura 3. Secções anatômicas da lâmina foliar de aroeira-vermelha sob diferentes condições de alagamento: T1 (A - D), T2 (E - H) e T3 (I - M). Detalhe do mesofilo (A, E, I), da nervura principal (B, F, J), dos tricomas secretores $(C, G, L)$, do parênquima lacunoso $(D, H, M)$ e da epiderme abaxial com estômato $(\mathrm{K})$. Os estômatos estão indicados por setas em D, E e K. Legendas: CB = célula basal; $\mathrm{CC}=$ células da cabeça; $\mathrm{CO}=$ colênquima; $\mathrm{CP}=$ célula do pescoço; $\mathrm{DS}=$ ducto secretor; $\mathrm{PL}=$ parênquima lacunoso; $\mathrm{PP}=$ parênquima paliçádico. Barras de escala: $25 \mu \mathrm{m}(\mathrm{C}, \mathrm{D}, \mathrm{G}, \mathrm{H}, \mathrm{K}, \mathrm{L}$, $\mathrm{M}), 50 \mu \mathrm{m}(\mathrm{A}, \mathrm{E}, \mathrm{I}), 100 \mu \mathrm{m}(\mathrm{B}, \mathrm{F}, \mathrm{J}) . \mathrm{T} 1$ : testemunha (plantas irrigadas diariamente), T2: alagamento parcial (plantas alagadas até o coleto) e T3: alagamento total (plantas submersas).

Figure 3. Sections the leaf anatomy of aoreira-vermelha under different flooding conditions: T1 (A - D), T2 (E - H) and T3 (I - M). Details mesophyll (A, E, I), the main vein (B, F, J), the trichomes (C, G, L), spongy parenchyma $(\mathrm{D}, \mathrm{H}, \mathrm{M})$ and lower epidermis with stomata $(\mathrm{K})$. The stomatum are indicated by arrows in $\mathrm{D}, \mathrm{E}$ and $\mathrm{K}$. Subtitles: $\mathrm{CB}=$ basal cell; $\mathrm{CC}=$ head cells; $\mathrm{CO}=$ collenchyma; $\mathrm{CP}=$ neck cell; $\mathrm{DS}=$ secretory duct; $\mathrm{PL}=$ spongy parenchyma; $\mathrm{PP}=$ palisade parenchyma. Scale bars: $25 \mu \mathrm{m}$ (C, D, G, H, K, L, M), 50 micron (A, E, I), 100 micron (B, F, J). T1: control (irrigated plants), T2: partial flooding (flooded plants up to the collar) and T3: total flooding (submerged plants). 
$\mathrm{Na}$ nervura principal ocorrem tricomas tectores unicelulares com paredes espessadas e com ponta aguda. No restante da superfície da lâmina foliar ocorrem tricomas glandulares clavados, formados por uma célula basal ao nível das ordinárias, uma célula-pescoço e a cabeça contendo três ou quatro camadas, cada uma com duas a quatro células, exceto a apical, que contém uma ou duas células (Figura 3C).

A epiderme é unisseriada, e subjacente a ambas as faces ocorre parênquima clorofiliano, divergindo das descrições anteriores para a espécie (CHIAMOLERA, 2008; DUARTE et al., 2006), em que se relata uma hipoderme.

O mesofilo é dorsiventral (Figura 3A), onde o parênquima paliçádico possui duas camadas celulares. A superior tem células mais alongadas, cujo conteúdo se cora de verde com azul de toluidina, indicando a presença de compostos fenólicos. O parênquima paliçádico chega a ocupar $60 \%$ do mesofilo, resultado semelhante ao observado por Duarte et al. (2006). O parênquima lacunoso possui três a cinco camadas de células isodiamétricas, delimitando espaços intercelulares menos conspícuos que os outros tratamentos (Figuras 3A, 3D).

A nervura principal é biconvexa e possui colênquima angular, e os feixes são colaterais e possuem ductos secretores imersos no floema (Figura 3B). Essa característica é descrita por Metcalfe e Chalk (1950) em gêneros de Anacardiaceae. Externamente a esse tecido, foi observado um arco formado por duas ou três camadas de células cujas paredes são espessadas e coram-se de azul claro com azul de toluidina (Figura 3B). Essas células, provavelmente, correspondem à bainha esclerenquimática incompleta em arco, descrita por Duarte et al. (2006). Esses mesmos autores descreveram colênquima anular em localização semelhante ao colênquima angular no presente trabalho. Essa divergência com os nossos resultados possivelmente se deve ao fato de as folhas aqui analisadas não estarem totalmente expandidas, portanto o colênquima angular pode ainda não ter completado o espessamento de suas paredes, tornando-se anular, conforme se relata na literatura (FAHN, 1985). Quanto às fibras da bainha, possivelmente ainda não estavam plenamente lignificadas, visto que não se coraram de verde com azul de toluidina.

No lúmen dos ductos não foi observada nenhuma secreção, o que quase certamente se deve a uma extração artefatual durante o processamento das amostras. Entretanto pode ocorrer algum resíduo celular. Essa característica sugere uma origem lisígena a tais ductos, porém são necessários estudos ontogenéticos para elucidar o desenvolvimento dessas estruturas e estudos histoquímicos para inferir a natureza de sua secreção.

As demais nervuras possuem, em secção transversal, um cordão de colênquima angular que se estende da bainha do feixe até a epiderme. Os feixes vasculares mais calibrosos também possuem ductos no floema, semelhantes aos da nervura principal.

Uma peculiaridade anatômica marcante das Anacardiaceae é a presença de canais/cavidades secretores em órgãos vegetativos e reprodutivos. Os canais dos órgãos vegetativos de Anacardiaceae podem ser encontrados no floema primário, secundário e na medula (METCALFE; CHALK, 1950). Esses canais/cavidades produzem substâncias de uso medicinal, industrial e com efeitos alergênicos (JUDD et al., 1999).

Diferentemente do restante da lâmina foliar, o bordo não apresenta estômatos. Nessa região ocorrem algumas células subepidérmicas com espessamento de parede que se coram de roxo com azul de toluidina.

Idioblastos contendo compostos fenólicos e drusas de oxalato de cálcio ocorrem por toda a lâmina foliar, principalmente associados ao floema.

No tratamento parcialmente alagado (T2), as paredes periclinais da epiderme são mais espessadas que as encontradas em T1, cujo formato se assemelha a lentes biconvexas (Figura 3E). Tal adaptação provavelmente atua concentrando os raios de luz para o mesofilo, conforme descrito por Bredenkamp e Van Wyk (1999) para Passerina (Thymelaeaceae).

A cutícula é mais delgada que no tratamento anterior. Os estômatos apresentam-se em um nível superior ao das células ordinárias (Figura 3E). De acordo com Esau (1976), a posição dos estômatos pode ser analisada em função das adaptações ecológicas da planta. Estômatos localizados acima do nível das demais células epidérmicas são associados a um ambiente com grande suprimento de água, enquanto estômatos localizados em depressões, em geral, indicam um hábitat caracterizado pelo baixo suprimento de água.

Os tricomas são idênticos aos descritos anteriormente, com o diferencial de apresentarem compostos fenólicos nas células da cabeça (Figura 3G). Muitos compostos fenólicos apresentam funções importantes nos vegetais, agindo como compostos de defesa contra situações de estresse (TAIZ; ZEIGER, 2004). Nos casos em que as plantas estão com estresse hídrico, os compostos fenólicos acumulados nos 
vacúolos garantem a manutenção do arcabouço celular e da integridade dos tecidos (APPEZZATO-DAGLÓRIA; CARMELO-GUERREIRO, 2003).

O mesofilo apresenta parênquima paliçádico com uma ou duas camadas celulares, contendo espaços intercelulares mais amplos que em T1 (Figura 3E). O parênquima lacunoso não difere no número de camadas, entretanto as células assumem formatos menos isodiamétricos, tendendo de formas alongadas a braciformes (Figura 3H). Consequentemente, os espaços intercelulares são mais numerosos e em maior tamanho que em T1. Os cloroplastos são maiores e em maior número que em T1, constatandose a presença de amido, sob luz polarizada, na região do mesofilo. O bordo foliar permanece com as mesmas características.

A nervura principal, embora com espessura semelhante à da amostra T1, possui um número maior de células. Essa condição sugere uma proliferação celular em detrimento de sua expansão (Figura 3F).

Os feixes vasculares são como em T1, com compostos fenólicos nas células da bainha do feixe e do floema em contato com o ducto (Figura 3F).

No tratamento totalmente alagado (T3), as células epidérmicas possuem paredes periclinais com espessamento maior que o apresentado nos tratamentos anteriores. Em alguns locais são tão espessadas a ponto de quase colabar o lúmen celular. Esse espessamento pode estar relacionado ao fator proteção contra um possível ataque de microrganismos presentes na água.

Os estômatos ocorrem em um nível pouco superior ao das células ordinárias, não sendo tão salientes quanto em T2 (Figura 3K). À primeira vista poderia se esperar que em T3 os estômatos fossem mais salientes que em T2, uma vez que a elevação dos estômatos aumentaria a ação das calotas de difusão (JARVIS; MCNAUGHTON, 1986) e, consequentemente, o fluxo transpiratório. Entretanto, os estômatos em T3 encontram-se submersos, ou seja, incapazes de atuarem na transpiração. A posição das células estomáticas normalmente está associada ao ambiente, sendo que em folhas submersas os estômatos podem estar ausentes (APPEZZATO-DA-GLÓRIA; CARMELO-GUERREIRO, 2003). Portanto, pode-se inferir que em $S$. terebinthifolius submetido ao alagamento total há um direcionamento adaptativo fenotípico a um ambiente anóxico, no qual a função transpiratória é inibida e, consequentemente, os estômatos tenderiam a um processo de atrofia.

A cutícula é mais delgada, de difícil visualização. É amplamente difundida a informação de que a cutícula é responsável pela proteção contra perda de água, mediante a impermeabilização das folhas (FAHN, 1985; GIFFORD; FOSTER, 1989; APPEZZATO-DA-GLÓRIA; CARMELO-GUERREIRO, 2003). Assim sendo, nas folhas submersas a impermeabilização epidérmica é desnecessária.

O mesofilo apresenta uma ou duas camadas de parênquima paliçádico, sendo que na superior prevalecem células contendo compostos fenólicos, conforme observado nos tratamentos anteriores. Os tricomas glandulares permanecem como descrito em T2, ou seja, contendo compostos fenólicos nas células da cabeça (Figura 3L). Provavelmente, o nível de alagamento em T2 já é estímulo suficiente para deflagrar a máxima produção de compostos fenólicos por esses tipos celulares.

De um modo geral, os espaços intercelulares no mesofilo são maiores que nos demais tratamentos (Figura 3I). No parênquima lacunoso, há agora o predomínio de células braciformes (Figura 3M). Esses sintomas são associados à ação do etileno, fitormônio gasoso produzido em condições de anoxia. Fenômeno semelhante de aumento de espaços intercelulares foi descrito no córtex radicular de Chorisia speciosa, o que foi interpretado como adaptação para uma maior difusão de oxigênio (BIANCHINI et al., 2000).

As nervuras são menos calibrosas que em T2 e em T1, observando-se uma redução dos tecidos de sustentação vasculares (Figura 3J), o que é comum em plantas higromórficas (APPEZZATO-DAGLÓRIA; CARMELO-GUERREIRO, 2003). Quanto ao tamanho celular, relata-se aumento de volume por ação do etileno (SALISBURY; ROSS, 1992). Não obstante, se observou no presente trabalho uma redução no tamanho das células das nervuras das plantas que crescem em condições de alagamento.

\section{CONCLUSÕES}

- As mudas de S. terebinthifolius desenvolveram modificações fenotípicas adaptativas nos dois níveis de saturação hídrica avaliados. Com o alagamento, foi observado aumento da espessura da base do caule, clorose e abscisão foliar e surgimento de lenticelas e raízes adventícias. Entretanto as mudas dessa espécie mostraram-se mais tolerantes ao alagamento parcial do que ao alagamento total no período de dez semanas. 
- De forma geral, para os parâmetros morfológicos avaliados após três semanas de alagamento, não foram observadas grandes modificações na morfologia das folhas, mostrando que esses parâmetros são inerentes a esse tipo de condição, ou, por outro lado, indicam certo grau de tolerância ao alagamento. Para a área foliar e AEF, houve diferença significativa entre os tratamentos apenas para a folha 3. Em T3, o teor de água foi maior e a espessura foliar menor. Quanto à densidade estomática, não houve diferença entre os tratamentos.

- Quanto aos aspectos anatômicos, observou-se uma redução na espessura do mesofilo e das nervuras, assim como a produção de compostos fenólicos por alguns tipos celulares. Os espaços intercelulares são progressivamente mais amplos nas plantas submetidas ao alagamento.

- S. terebinthifolius possui grande potencial de utilização em recuperação de áreas ripárias, uma vez que a plasticidade fenotípica apresentada por mudas dessa espécie levou ao desenvolvimento de diversas adaptações morfoanatômicas, em função dos diferentes níveis de saturação hídrica em função do tempo.

\section{REFERÊNCIAS}

APPEZZATO-DA-GLÓRIA, B.; CARMELO-GUERREIRO, S. M. Anatomia vegetal. Viçosa, Ed. UFV, 438 p. 2003.

ARAÚJO, J. F.; HARIDASAN, M. Deciduidade e nutrientes em espécies nativas do cerrado. Revista Brasil. Bot., v. 30, n. 3, p. 533 - 542, 2007.

ARMSTRONG, W.; BRANDLE, R.; JACKSON, M. B. Mechanisms of flood tolerance in plants. Acta Bot. Neerl., v. 43, n. 4, p. 307 - 358, 1994.

ARRUDA, G. M. T.; CALBO, M. E. R. Efeitos da inundação no crescimento, trocas gasosas e porosidade radicular da carnaúba (Copernicia prunifera (Mill.) H. E. Moore). Acta Bot. Bras., v. 18, n. 2, p. 219 - 224, 2004.

BATISTA, C. U. N.; MEDRI, M. E.; BIANCHINI, E.; MEDRI, C.; PIMENTA, J. A. Tolerância à inundação de Cecropia pachystachya Trec. (Cecropiaceae): aspectos ecofisiológicos e morfoanatômicos. Acta Bot. Bras., v. 22, n. 1, p. 91 - 98, 2008.

BERLYN, G. P.; MIKSCHE, J. P. Botanical Microtechnique and Cytochemistry. Iowa: Iowa State University Press, 1976.

BIANCHINI, E.; MEDRI, M. E.; PIMENTA, J. A.; GILONI, P. C.; KOLB, R. M.; CORREA, G. T. Anatomical alterations in plants of Chorisia speciosa A. St.-Hil. Submitted to flooding. Revista Interciência, v. 25, n. 9, p. 436 - 441, 2000.

BOEGER, M. R. T.; KAEHLER, M.; MELO JÚNIOR, J. C. F.; GOMES, M. Z.; OLIVEIRA, L. S.; CHAVES, C. R. M.; SCHOTTZ, E. S. Estrutura foliar de seis espécies do sub-bosque de um remanescente de Floresta Ombrófila Mista. Hoehnea, v. 33, n. 4, p. 521 - 531, 2006.

BREDENKAMP, C. L.; VAN WYK, A. E. Structure of mucilaginous epidermal cell walls in Passerina (Thymelaeaceae). Bot. J. Linn. Soc., v. 129, p. 223 - 238, 1999.

CRAWFORD, R. M. M. Oxygen availability as an ecological limit to plant distribution. Advances in Ecological Research, v. 23, p. 93 - 185, 1992.

CHIAMOLERA, L. B. Comportamento de espécies arbóreas nativas implantadas em áreas com diferentes graus de sucessão no Reservatório Iraí, PR. 133 p. Tese (Doutorado em Silvicultura) Universidade Federal do Paraná, Curitiba, 2008.

CIRILO, L. F.; MEDRI, M. E. Estudos da tolerância a hipoxia em populações naturais de Parapiptadenia rigida Benth. Brenan (Leguminosae-Mimosoidae). In: ENCONTRO ANUAL DE INICIAÇÃO CIENTÍFICA, 11., 2002, Maringá. Anais... Maringá, 2002.

DAVANSO, V. M.; SOUZA, L. A.; MEDRI, M. E.; PIMENTA, J. A.; BIANCHINI, E. Photosynthesis, growth and development of Tabebuia avellanedae Lor. Ex Griseb. (Bignoniaceae) in flooded soil. Braz. 
Arch. of Biol. and Technol., v. 45, n. 3, p. 375 - 384, 2002.

DAVANSO, V. M.; MEDRI, M. E.; SOUZA, L. A.; COLLI, S. Tabebuia avellanedae Lor. Ex Griseb. (Bignoniaceae) submitted at the flooding and the "Ethrel" and silver nitrate application. Braz. Arch. of Biol. and Technol., v. 46, n. 1, p. 57 - 64, 2003.

DIAS, J.; PIMENTA, J. A.; MEDRI, M. E. Aspectos morfológicos e anatômicos de folhas de sol e sombra de Schinus terebinthifolius Raddi (Anacardiaceae). In: CONGRESSO DE ECOLOGIA DO BRASIL, 6., 2003, Fortaleza. Anais..., Fortaleza, 2003. p. 455 - 457. (Capítulo III Florestas Estacionais).

DUARTE, M. R.; TOLEDO, M. G.; OLIVEIRA, R. La B. Diagnose morfoanatômica de aroeira (Schinus terebinthifolius Raddi, Anacardiaceae). Revista Visão Acadêmica, Curitiba, v. 7, n. 2, p. 5 - 13, 2006.

ESAU, K. Anatomia das plantas com sementes. Tradução: Berta Lange de Morretes. São Paulo: Edgard Blucher, 1976.

FAHN, A. Anatomia vegetal. Madrid: Ed. Pirâmides, 599 p. 1985.

GAVILANES, M. L.; CASTRO, E. M. Histologia e anatomia vegetal. Lavras: UFLA/FAEPE, 1998. 90 p. (Curso de Pós-Graduação Latu Sensu: Biologia).

GIFFORD, E. M.; FOSTER, A. S. Morphology and evolution of vascular plants. 3 ed. W. H. Freeman and Company, 1989.

HURLBERT, S. H. Pseudoreplication and the design of ecological field experiments. Ecological Monographs, v. 54, p. 187 - 211, 1984.

ISHIDA, F. Y.; OLIVEIRA, L. E. M; CARVALHO, C. J. R.; ALVES, J. D. Efeitos da inundação parcial e total sobre o crescimento de clorofila e fluorescência de Setaria anceps e Paspalum repens. Revista Ciência Agrotec, Lavras, v. 26, n. 6, p. 1152 - 1159, 2002.

JARVIS, P. G.; MCNAUGHTON, K. G. Stomatal control of transpiration: scaling up from leaf to region. In: Advances in ecological research, v. 15, 1986.

JOHANSEN, D. A. Plant microtechnique. New York: McGraw-Hill Book, 1940. 41 p.

JUDD, W. S.; CAMPBElL, C. S.; KellogG, E. A.; STEVENS, P. F.; DONOGHUE, M. J. Plant systematics. A phylogenetic approach. Massachusetts: Sinauer Associates, 1999.

KOLB, R. M.; MEDRI, M. E.; BIANCHINI, E.; PIMENTA, J. A.; GILONI, P. C.; CORREA, G. T. Anatomia ecológica de Sebastiania commersoniana (Baillon) Smith \& Downs (Euphorbiaceae) submetida ao alagamento. Revta Brasil. Bot., São Paulo, v. 21, n. 3, p. 305 - 312, 1998.

KOZLOWSKI, T. T. Responses of woody plants to flooding. In: KOZLOWSKI, T. T. (Ed.). Flooding and plant growth. London: Academic Press, 1984. p. 129 - 163.

Physiological-ecological impacts of flooding on riparian forest ecosystems.Wetlands, v. 22, p. 550 - 561, 2002.

LARCHER, W. Ecofisiologia vegetal. São Carlos: RIMA, 2000. 531 p.

LEITÃO, C. A. E.; CORTELAZZO, A. L. An inexpensive alternative equipment for the plant material embedding in the paraffin under the vacuum. Braz. Arch. Biol. Technol., v. 51, n. 5, p. 1011 - 1014, Sept.-Oct./2008.

LEITÃO, C. A. E.; MEIRA, R. M. S. A.; AZEVEDO, A. A.; ARAÚJO, J. M.; SILVA, K. L. F.; COLLEVATTI, R. G. Anatomy of the floral, bract, and foliar nectaries of Triumfetta semitriloba (Tiliaceae). Can. J. Bot., Canadá, v. 83, p. 279 - 286, 2005.

LOBO, P. C.; JOLY, C. A. Aspectos ecofisiológicos da vegetação de mata ciliar do sudeste do Brasil. In: Matas ciliares: conservação e recuperação. 2. ed. São Paulo: EDUSP/FAPESP, 2001.

LORENZI, H. Árvores brasileiras: manual de identificação e cultivo de plantas arbóreas nativas do 
Brasil. 4. ed. Nova Odessa, SP: Instituto Plantarum, 2002. v. 1.

MEDRI, M. E.; BIANCHINI, E.; PIMENTA, J. A.; DELGADO, M. T.; CORREA, G. T. Aspectos morfoanatômicos e fisiológicos de Peltophorum dubium (Spr.) Taub. submetida ao alagamento e aplicação de ethrel. Revta. Brasil. de Bot., v. 21, p. 261 - 267, 1998.

MEDRI, M. E.; FERREIRA, A. C.; KOLB, R. M.; BIANCHINI, E.; PIMENTA, J. A.; DAVANSOFABRO, V. M.; MEDRI, C. Alterações morfoanatômicas em plantas de Lithraea molleoides (Vell.) Engl. submetidas ao alagamento. Acta Sci. Biol. Sci., Maringá, v. 29, n. 1, p. 15 - 22, 2007.

METCALFE, C. R.; CHALK, L. Anatomy of the dicotyledons: leaves, stem, and wood in relation to taxonomy. Oxford: Clarendon, 1950. v. 1. p. 452 - 462.

PEZESHKI, S. R. Plant response to flooding. In: WILKINSON, R. E. (Ed.). Plant-environment interactions. New York: Marcel Dekker, 1994. p. 289 - 321.

PIMENTA, J. A.; MEDRI, M. E.; BIANCHINI, E.; MULLER, C.; OKAMOTO, J. M.; FRANCISCONI, L. M. J.; CORREA, G. T. Aspectos da morfoanatomia e fisiologia de Jacaranda puberula Cham. (Bignoniaceae) em condições de hipoxia. Revta. Brasil. Bot., São Paulo, v. 19, n. 2, p. 215 - $220,1996$.

RAVEN, P. H.; EVERT, R. F.; EICHHORN, S. E. Biologia vegetal. 6. ed. Rio de Janeiro: Guanabara Koogan, 728 p. 2001.

SALISBURY, F. B.; ROSS, C. W. Plant physiology. California: Wadsworth Publishing Company, 1992.

SANTIAGO, E. J. A.; PINTO, J. E. B. P.; CASTRO, E. M.; LAMEIRA, O. A.; CONCEIÇÃO, H. E. O. da.; GAVILANES, M. L. Aspectos da anatomia foliar da pimenta-longa (Piper hispidinervium C. DC.) sob diferentes condições de luminosidade. Ciênc. Agrotec., Lavras, v. 25, n. 5, p. 1035 - 1042, 2001.

SUTCLIFFE, J. F. As plantas e a água. São Paulo: EDUSP, 126 p. 1980.

TAIZ, L.; ZEIGER, E. Fisiologia vegetal. Tradução: Eliane Romanato Santarém. 3. ed. Porto Alegre: Artmed, 719 p. 2004.

VIDAL, B. C. Acid glycosaminoglycans and endochondral ossification: microspectrophotometric evaluation and macromolecular orientation. Cell. Mol. Biol., v. 22, p. 45 - 64, 1977.

WITKOWSKI, E. T. F.; LAMONT, B. B. Leaf specific mass confounds leaf density and thickness. Oecologia, v. 88, p. 486 - 493. 1991. 
